\title{
Recepção da filosofia de Nietzsche na obra de Celso Furtado
}

\author{
Geraldo Dias*
}

Resumo: Tendo em conta que 2020 foi o ano de celebração do centenário de nascimento de Celso Furtado, como singela homenagem, neste artigo procuramos oferecer uma introdução preliminar sobre a recepção da filosofia de Nietzsche na obra do economista brasileiro. Celso Furtado é um dos pensadores mais influentes no campo da economia-política na América Latina. Mas ninguém ainda pesquisou a dimensão filosófica de seu pensamento. Não obstante, é possível discorrer que ele pensou a economia sob um ponto de vista crítico-filosófico. Para comprovar essa hipótese, pretendemos evidenciar três aspectos conceituais por ele apropriados da filosofia de Nietzsche. São eles: a criatividade e/ ou criação (Schaffung), para pensar o seu papel como agente motor de desenvolvimento da civilização industrial; a transvaloração de todos os valores (Umwerthung aller Werthe), para pensar a relevância dos valores morais para os centros de decisões dos meios e dos fins da produção e distribuição do capital; e o perspectivismo (Perspektivismus), para pensar a economia como uma totalidade composta por múltiplas perspectivas estruturais.

Palavras-chave: Nietzsche, recepção, Celso Furtado, criatividade, valores morais, perspectivismo.

* Faculdade de Filosofia, Ciências de Letras de Cajazeiras (FAFIC), Cajazeiras, Paraíba, Brasil. ORCID https://orcid.org/0000-0001-6846-036X

Correio eletrônico: ge.pdias@hotmail.com 
Dias, G.

\section{Introdução}

O objetivo aqui perseguido consiste em despontar uma vista geral do pensamento econômico de Nietzsche e da maneira pela qual esse aspecto de sua filosofia foi recebido pelo economista Celso Furtado. Cabe examinar a hipótese de que a filosofia nietzschiana foi recebida pelo economista paraibano para pensar a relevância da criatividade no processo de desenvolvimento econômico da civilização industrial e dos valores morais para os centros decisórios dos meios e dos fins da produção e da distribuição de capital, no livro Criatividade e dependência na civilização industrial, de 1978, bem como para pensar a formação e o desenvolvimento da economia a partir de uma visão perspectivista, presente em diversos textos, desde o clássico Formação econômica do Brasil, de 1959. Uma verificação dessa hipótese se justifica, entre outros motivos, pelo fato de ainda não haver investigação aprofundada acerca do que Nietzsche pensava sobre economia, nem a maneira pela qual esse aspecto de seu pensamento foi recebido.

Malgrado a lacuna, ponderações de Nietzsche sobre economia e a maneira pela qual elas foram recebidas podem ser reconstituídas. Para tanto, levamos em conta as fontes de consulta de Celso Furtado e as confrontamos com a literatura especializada atual e a edição das obras de Nietzsche estabelecida por Giorgio Colli e Mazzino Montinari. Igualmente, procuramos conjugar a prática conciliada dos métodos genético e estrutural (portanto não tanto à maneira do método estrutural dogmático de Victor Goldschmidt, mas antes à maneira de quem aqui é também homenageado: Scalett Marton, com quem esse método deixa de ser uma camisa de força e passa a ser uma "experiência de formação", junto ao GEN - Grupo de Estudos Nietzsche, Marton, 2012, p. 310), aplicados à leitura dos escritos de Nietzsche, com a metodologia da recepção filosófica, conforme a definição da filósofa Agnes Heller. A recepção de uma filosofia não é um ato de pura especulação, é antes a satisfação de um carecimento. 
Ora, é possível definir a filosofia como objetivação de necessidades da existência humana. Afinal, "Toda esfera de objetivação satisfaz um carecimento qualquer [...]. E, dado que a filosofia (como a arte, a teoria científica e, em parte, a religião) constitui um sistema de objetivações autônomo, em si concluído, a satisfação do carecimento ocorre para ela sob a forma de recepção". Em A filosofia radical, Heller demonstra ser possível distinguir, ordenar e delimitar dois tipos fundamentais de recepção da filosofia. Definida enquanto esfera de objetivação constituída por três momentos radicais: como pensar, como agir e como viver, a filosofia incita seus receptores a refletirem como pensar, como agir e como viver. Entretanto, se no interior de uma filosofia esses três momentos são unidos e inseparáveis, na sua recepção pode ocorrer a separação. Deste modo, uma filosofia pode ser apropriada em sua totalidade, configurando uma recepção completa, ou em partes separadas, configurando uma recepção parcial. Neste artigo, realizamos a nossa análise sob o ponto de vista da recepção filosófica parcial. Entre as variações da recepção parcial, consta a recepção avaliativo-cognoscitiva; assim, argumentamos que Celso Furtado realizou uma recepção da filosofia de Nietzsche enquanto guia de conhecimento, isto é, quando a filosofia fornece à ciência determinados valores. Com Celso Furtado ocorreu algo à semelhança dos "fisiocratas" e dos "grandes representantes da economia clássica inglesa [que] receberam com plena consciência os valores de diversas filosofias, para deles fazer o fundamento teórico de seus sistemas" (Heller, 1983, p. 13-50).

Uma aplicação conciliada desses métodos (genético-estruturalrecepção filosófica) nos permite verificar que Nietzsche realizou uma atinada crítica da "cultura industrial" (industriellen Cultur) e que ela foi amplamente recebida; mas que nem sempre se compreendeu bem o porquê ou em visto do que ele realizou essa crítica. Se, por um lado, sua apreciação negativa da cultura industrial foi recebida e aproveitada por diversos economistas, eles mesmos não investigaram 
Dias, G.

qual seria, por outro lado, a sua alternativa de modelo econômico. Nietzsche rejeitou a economia liberal e a planificada, entre outras razões, por ambas voltarem-se ao que chamava de felicidade do maior número. Ele deixou abundantes reflexões sobre os efeitos decorrentes da economia liberal e da economia escravista para o que denomina cultura (Bildung), reflexões que ainda permanecem relevantes e um estímulo para seus receptores, não apenas da área de economia.

Dito isso, cabe informar que a exposição deste artigo será divindade em quadro etapas. Na primeira, examinamos a maneira pela qual a filosofia de Nietzsche foi recebida por Celso Furtado para pensar o papel da criatividade e dos valores morais no desenvolvimento econômico da civilização industrial; na segunda, evidenciamos o descompasso de Nietzsche entre a sua crítica da economia liberal e a sua afirmação da economia escravista; em seguida, exporemos o curto-circuito historiográfico que acompanha esse descompasso a partir da denominada "desorrorização" de Nietzsche e, por fim, como a recepção de sua filosofia, realizada por Celso Furtado, superou esse descompasso e curto-circuito através de uma visão perspectivista da economia.

\section{Nietzsche na formação e na obra de Celso Furtado}

Embora não haja no conjunto da obra de Nietzsche uma abordagem sistemática de problemas de ordem econômica, nem vocabulário típico dos pensadores dessa área, ainda assim, as suas reflexões de teor econômico alimentaram e guiaram a pesquisa de economistas. Pensamos aqui em economistas que Celso Furtado leu. É muito provável que ele tenha tomado conhecimento da ideia de destruição criativa, de procedência nietzschiana, presente nas teorias econômicas de Werner Sombart e Joseph Schumpeter. A expressão se tornou uma das marcas de Schumpeter. Entre as características de sua teoria econômica, há o empreendedor, um promotor de mudanças cuja a sua vontade de potência e de destruição criativa remontam 
a Nietzsche. Contudo, o primeiro uso do termo em economia deve ser atribuído a Sombart. Ele acreditava que a vontade de potência nietzschiana é essencialmente vontade de criar e, consequentemente, a principal força motriz do desenvolvimento econômico. $\mathrm{O}$ conceito de destruição criativa parecia adequado para descrever o processo pelo qual as tecnologias da informação e da comunicação destruíram as soluções tecnológicas anteriores e as antigas empresas, abrindo espaço para as novas (Reinert, 2006, p. 55-135). O ambiente francês no qual Celso Furtado se formou e escreveu fornece indícios da maneira pela qual também ele recebeu o pensamento de Nietzsche para fundamento teórico de seu sistema conceitual, empenhado em pensar o problema do subdesenvolvimento das economias periféricas ${ }^{1}$.

Celso Furtado realizou seu doutorado em Economia pela Universidade de Paris-Sorbonne, em 1948. Sob a influência de Maurice Byé, pesquisou a economia colonial brasileira no período do açúcar e sua relevância para o comércio internacional. Cultivado no ambiente de Paris do pós-guerra, motivado pelo interesse em conhecer o mundo, frequentou a biblioteca e cursos do Institut d'Études Politiques, na Sciences Po e, entre as salas da Sorbonne e seus arredores, pôde desfrutar de uma atmosfera intelectual na qual a filosofia de Nietzsche (e a ela associada a questão do sentido do ato criador) já estava instalada, como ele mesmo faz lembrar em sua autobiografia. Na ocasião, tomou contato com os existencialistas "obcecados" por Sartre; muito atento, identifica neles o que chama de "a volta a Nietzsche: o homem como criador de valores; o homem

1 A biblioteca particular de Celso Furtado abriga obras de Sombart, de Schumpeter e de Nietzsche. Deste último, consta parte de sua correspondência, além de livros e artigos de comentadores e intérpretes. Esse acervo é composto por textos transcritos em diferentes traduções, sobretudo em francês, inglês e português. As traduções das obras, muitas delas, já feitas a partir dos textos da edição preparada por Giorgio Colli e Mazzino Montinari. Há exemplares com anotações manuscritas e trechos sublinhados por Celso Furtado, como é o caso em Ainsi parlait Zarathoustra, na tradução de Geneviève Blanquis, em Nietzsche, philosopher, psychologist, antichrist, de Walter Kaufmann, e em La destruction de la raison, de Lukács, cf. Biblioteca Celso Furtado. Pesquisa realizada no Consulta ao acervo. Acessos realizados no período de 2019 e 2020, no site: http://www.bibliotecacelsofurtado.org.br/ 
Dias, G.

começo e fim de tudo"; eram os seus anos "maravilhosos de boêmia filosófica" (Furtado, 2014, p. 39-570). Depois, também fará a sua volta a Nietzsche, com o qual pensará a civilização industrial como sendo marcada pela capacidade inventiva, canalizada para a criação tecnológica, vetor de sua força expansiva, mas que, ao mesmo tempo, concorre para a destruição de valores e a supressão da própria capacidade criativa. Celso Furtado julga que sem levar em conta o poder criativo, imanente à vida social, ficaríamos limitados a uma ilusão econômica, a um mero sistema de cálculos e equações.

Essa insistência na importância dos valores morais e da criatividade no desenvolvimento da economia remonta a Nietzsche. Preocupado em oferecer uma visão de conjunto dos processos econômicos, sempre esteve no horizonte de Furtado "pôr em evidência o sistema de valores que existe, aceito ou imposto, em toda ordenação econômica". Esforço reconhecido como um elemento diferenciador. Ele inclui nas suas reflexões os fatores não-econômicos e têm em conta sua relevância para os centros de controle de decisões que levam à transformação dos conjuntos econômicos. Para ele "o nãoeconômico traduz a capacidade do homem para criar a história e inovar" (Furtado, [1967] 1983, p. 7). Distingue que no centro da reflexão de Nietzsche "está a preocupação com os valores, a ansiedade com a redefinição dos valores, a identificação dos fins" . Mobiliza conceitos do filósofo, como a transvaloração de todos os valores, o antagonismo do gênio dionisíaco e da ciência alexandrinaracionalista para, em busca de sua própria visão global da economia, examinar o desenvolvimento histórico que culminou na civilização industrial, marcada pela criatividade e dependência aos meios. Julga não haver sistema econômico sem um conjunto de valores que definam os meios e os fins de seu desenvolvimento. Considera

\footnotetext{
2 Para Furtado, em um "mundo que se ordena em função dos meios", a "solidão" de Nietzsche "teria que ser total", por sua "percepção aguda de que nossa civilização, ao subordinar os fins aos meios, avança aceleradamente para um despenhadeiro", cf. Furtado, [1978] 2008, p. 202-5. Como podemos acompanhar, traduz a expressão Umwerthung aller Werthe por "redefinição dos valores".
}

150 | Cad. Nietzsche, Guarulhos/Porto Seguro, v.42, n.1, p. 145-172, janeiro/abril, 2021. 
que toda redefinição (transvaloração) de valores implica alteração na economia, redefinindo os seus fins.

Celso Furtado identificou na crítica dirigida por Nietzsche contra o espírito acumulativo da civilização industrial uma angustiante luta contra a subordinação dos impulsos criativos aos meios captadores de excedente. Observou que na civilização industrial a capacidade das pessoas para inventar valores finais que ampliem a visão de si mesmas e do mundo começa a declinar à medida em que a criatividade é subordinada ao processo acumulativo. Não admira que a crítica da área reconheça nele um autor que vai além da sua condição de economista político e se torna um pensador universal. Ele não se preocupava somente com o desenvolvimento econômico, com o pleno emprego ou com a repartição da renda, mas com o próprio destino humano. Em Criatividade e dependência, Furtado demonstra que os sistemas globais de cultura periféricos foram tolhidos por uma série de mecanismos institucionais e em virtude disso é que ficaram amputados e dependentes, incapazes de ímpetos criativos a partir de suas potencialidades internas. Não se trata de um livro de pura reflexão, resulta antes de uma forma crítico-filosófica de pensar e da luta do autor contra a dependência, de sua atuação em favor da assunção de uma "forma de liberação da capacidade criadora de um povo" (Quintela, 2020, p. 17). Seu objetivo já não era tanto refletir sobre o desenvolvimento econômico, mas sobre a realização da liberdade por meio da livre criatividade. É em vista desse objetivo que Nietzsche comparece no livro. Sem dúvida um pensador que contribui para confrontar a proposta de Celso Furtado de libertação integral do homem contemporâneo ${ }^{3}$.

Segundo a interpretação de Celso Furtado, desde $O$ nascimento da tragédia, Nietzsche começa a criar uma série de símbolos para

3 Alfredo Bosi argumentou que a "aspiração" de Celso Furtado no pensamento de Nietzsche "pode ser assim formulada: que a atual submissão dos fins do ser humano aos meios seja revertida em prol de uma transmutação dos valores que regem a barbárie do consumismo de massas e a insensibilidade dos defensores do capital internacional”, cf. Bosi, 2008, p. 31. 
Dias, G.

denunciar o perigo da cada vez mais preponderante da subordinação dos fins aos meios, da criatividade à racionalidade, patente na sua crítica da ascensão do homem teórico em detrimento do gênio trágico. Racionalidade criticada por ter adquirido lugar de destaque no desenvolvimento do processo de acumulação. Exilado em Paris, no final dos anos 1970, Celso Furtado se apropriou do pensamento de Nietzsche para discorrer sobre as sombras projetadas pela emergência e difusão da civilização industrial, sobre as suas relações entre a acumulação e a racionalidade. Eis o objetivo de Criatividade e dependência, livro no qual Celso argumenta que o predomínio da razão teórica, em detrimento da criatividade trágica, foi fundamental para o avanço da civilização industrial, passando a condicionar para os seus fins técnicos e instrumentalizáveis todo impulso criador. Toda atividade criadora, então, passou a ficar a serviço da acumulação, que tende a submeter o próprio agente criador (o artista, o cientista) ao seu sistema. Celso Furtado alertou que o predomínio da economia decorrente dessa racionalidade exclui as possibilidades de uma perspectiva econômica global dos processos a ela submetidos e interdita o livre exercício da criatividade.

Em Criatividade e dependência, Nietzsche aparece como o representante desesperado dessa condição de "destruição da capacidade criadora do homem", rumo à sua própria "desumanização". Na leitura de Furtado, desde $O$ nascimento da tragédia Nietzsche já projetava a ideia de que as forças que em nossa civilização engendram a racionalidade conduzem concomitantemente à destruição da capacidade criadora. Entende que a "parábola do homem louco, introduzida na Gaia ciência, ilustra a agudeza da percepção do impasse a que chegara o homem numa civilização fundada na preeminência da lógica dos meios", quando "ainda parecia insanidade duvidar de que a razão era o princípio unificador de uma civilização que conduzia ao desenvolvimento de todas as potencialidades do homem". $\mathrm{Na}$ medida em que a criatividade se transformou em instrumento 
de ativação do processo de acumulação, Furtado julga que nesse "contexto adquire inescapável significação a pergunta de Zaratustra: liberdade para quê?"4. Nietzsche lhe aparece como o profeta capaz de forçar o homem a assumir a liberdade, "capacitando-se para autotransformar-se", pois "nele ligam-se intimamente as ideias de liberdade e de criatividade". Nessa direção, Celso Furtado assevera:

O espaço da cultura está delimitado pela ação criadora do homem, a qual expressa a sua liberdade. É nas formas que assume a criatividade que podemos encontrar a chave para captar as tendências mais profundas da nossa civilização. Ora, por um ou outro caminho essas formas tenderam a gravitar em torno do processo de acumulação [...]. A descentralização de decisões e a competitividade em todos os níveis, inerentes à economia de mercado, estimulam e mesmo exacerbam a iniciativa individual e, com esta, a inventividade pessoal. O fluxo de inovações que caracteriza essa economia é visto como um continuado esforço para ampliar o horizonte de possibilidades do homem e libertá-lo das peias que o submetem à natureza. Colocar a serviço da satisfação das necessidades humanas a vontade de poder do homem: eis o projeto de ordem social subjacente à economia de mercado que alcançou plena maturidade no século XIX. Ora, uma observação mais atenta desse sistema logo põe em evidência que nele a criatividade está subordinada à lógica dos meios, pois o conceito de necessidade humana não possui significado preciso e é definido à conveniência desses meios. Dessa forma, a liberdade assume o caráter de instrumento [...] (Furtado, [1978] 2008, p. 204-8).

Em conformidade com seu período e suas fontes de acesso às obras de Nietzsche, Celso Furtado compreende o conceito "vontade de poder" (Wille zur Macht) como domínio, poder político-econômico e capacidade criadora. Não parece desconhecer inteiramente que a orientação econômica visada por Nietzsche se caracteriza, precisamente, como vontade de potência, compreendida não somente como força criadora a serviço da satisfação das necessidades humanas e de sua conservação. Mas Celso Furtado deixa em suspenso qual

4 Neste ponto, Celso Furtado cita a seção "Do caminho do criador", cf. Za/ZA I, KSA 4.81.

Cad. Nietzsche, Guarulhos/Porto Seguro, v.42, n.1, p. 145-172, janeiro/abril, 2021.| 153 
Dias, G.

seria a perspectiva econômica pensada por Nietzsche e se a cultura por ele almejada concede espaço para o avanço da emancipação econômica para todos, capaz, enfim, de propiciar o livre exercício da criatividade.

Em sua busca de uma perspectiva ampla da economia, Furtado valoriza a revolta de Nietzsche contra o culto da ciência alexandrina em detrimento do gênio trágico como uma maneira de evidenciar os perigos da civilização industrial. Tendo isso em conta, o economista paraibano procurou pensar uma forma de criatividade que não estivesse subordinada à acumulação, mas que correspondesse a um ato de afirmação pessoal, capaz de vincular moralmente o criador à obra. Cabe perguntar, porém, a quem Nietzsche autorizaria uma forma de criatividade livre, subjacente ao descompasso da sua crítica da economia liberal e da sua afirmação da economia escravista e, em seguida, como a recepção de seu pensamento por Celso Furtado supera o curto-circuito historiográfico causado por esse descompasso, através de uma visão perspectivista da economia ${ }^{5}$.

\section{Crítica da economia liberal e afirmação da economia escravista}

Ao longo de sua obra, nota-se que Nietzsche combate os efeitos da implantação do capitalismo no âmbito cultural da Alemanha e, mais amplamente, da Europa. De início, contribui de forma entusiástica para a vitória alemã sobre França em 1871, mas logo percebe que essa vitória colabora para a industrialização da Alemanha e tende, assim,

\footnotetext{
5 Na quarta etapa, veremos que a noção furtadiana de "perspectiva ampla" mantém certa proximidade como o conceito de perspectivismo de Nietzsche, na acepção geral definida pelas duas teses de António Marques: $1^{\text {a }}$ ) no sentido de o perspectivismo ser uma característica fundamental do pensamento filosófico da época moderna até nossos dias, sendo Nietzsche o pensador que radicalizou até os limites essa mesma característica e $2^{\text {a }}$ ) que o perspectivismo tem uma qualidade niilista, pois supõe a consciência generalizada do caráter instrumental do conhecimento, sendo essa qualidade niilista capaz de proporcionar um autoconhecimento que é condição de superação do próprio niilismo, cf. Marques, 2003, p. 09.
}

154 | Cad. Nietzsche, Guarulhos/Porto Seguro, v.42, n.1, p. 145-172, janeiro/abril, 2021. 
a colocá-la no mesmo nível econômico da França e da Inglaterra, contribuindo também para prejudicar a cultura alemã, ao promover sua massificação. A seguir, critica os dois modelos econômicos predominantes: o liberalismo e o socialismo, submetendo-os ao seu procedimento genealógico, que enfatiza os móveis internos do ser humano em detrimento das condições socioeconômicas, com vistas a uma concepção de cultura (Bildung) oposta à da civilização industrial (Silva Júnior, 2007, p. 173-182).

Já em $O$ nascimento da tragédia, Nietzsche reconhece a necessidade do modo de produção escravista para o desenvolvimento durável de uma cultura: "a cultura alexandrina necessita de uma classe escrava para existir duradouramente"; "mas", à diferença da cultura grega antiga, "nega, em sua visão otimista da existência, a necessidade de tal classe" (GT/NT, §18, KSA 1.117). No texto $O$ estado grego, avalia que mesmo que os gregos tivessem sido "arruinados porque mantinham escravos" de mais, "o oposto é ainda mais certo: seremos destruídos pela falta de escravidão" (CV/CP, KSA 1.764). Ele "julga ver desdobramentos nefastos provocados pelo término da escravidão", capazes de cessar "privilégios sociais necessários ao cultivo do espírito, que propiciavam o ócio necessário a um seguimento preciso da sociedade alemã"6.

Já as obras publicadas por Nietzsche entre os anos 1878 e 1880 apresentam um pensamento econômico sobre a Europa de feição mais positiva. É o momento em que consente a possibilidade do Estado liberal, democraticamente limitado, sem sufrágio universal, com limitação do direito ao voto (WS/AS, §293, KSA 2.685). Diante da crescente valorização do sistema democrático e sua concorrência com o sistema socialista, ambos edificados na necessidade do respeito à igualdade de direitos civis, políticos e sociais, ele aposta

6 Silva Júnior, 2018, p. 30. Nietzsche conhecia, provavelmente, fontes sobre o número de escravos na Grécia. Estudos atuais indicam que o "número de escravos existentes na Grécia Antiga" "girava em torno de 60.000 a 80. 000, enquanto o número de cidadãos oscilava em torno de 40.000 a 60. 000", cf. Brugnera, 1998, p. 34 . 
Dias, G.

num futuro no qual o progresso econômico é possível. Recomenda procedimentos gerais para evitar grandes desigualdades econômicas entre os indivíduos, como identificar a necessidade de introdução na gestão da comunidade uma legislação fiscalizadora, para que não fique sob o domínio de particulares todos os ramos do transporte e do comércio que favoreçam o acúmulo de grandes fortunas (WS/ AS, §285, KSA 2.681). Nesse breve otimismo ocorre, idealmente, a "vitória da democracia", frente ao maior dos perigos: o nacionalismo e o socialismo (WS/AS, §292, KSA 2.683-4). Mas para que essa democracia possa garantir independência para o maior número, terá de abolir os grandes possuidores, os ricos, e os pobres. Para isso, Nietzsche encontra saída no direito político, mais precisamente no sistema eleitoral. Trata-se de retirar dos ricos e dos pobres o direito de votar (WS/AS, §293, KSA 2.685). Essas reflexões dividem espaço com outras, menos otimistas, nas quais a economia não deve separarse da cultura e dos costumes; quando divide a sociedade em nobres/ aristocratas, burgueses e proletariado, sendo consentido o direito à posse somente aos que sabem fazer uso do tempo livre, isto é, do ócio criativo, eis a razão da proposta de limitação da riqueza e da distribuição da propriedade segundo critérios elitistas (VM/OS, $\S 310$, KSA 2.502).

No conjunto das obras do período intermediário (1878-1882), a visão de Nietzsche acerca da economia é generalista, não privilegia nenhum aspecto específico. Avalia que a ideia de progresso da fantasia romântica pertence à cultura antiga e que ela tende a alimentar as culturas nacionais fechadas. Julga que o progresso não é algo que "deva necessariamente ocorrer", mas consente a sua possibilidade lógica. Afinal, diferente da cultura antiga, na qual ocorria o desenvolvimento inconsciente das forças produtivas, na cultura moderna, os homens decidem de modo consciente a respeito do desenvolvimento da cultura (MA I/HH I, §24, KSA 2.45). Dá como morta a crença numa harmonia universal, seja no livre-comércio, 
seja na moralidade. A partir de estudos sobre a necessidade de um conhecimento das condições de cultura superior, opta por uma visão geral das especificidades e de um governo global consciente (MA I/ HH I, §25, KSA 2.46). Exorta o iluminismo de Voltaire e repudia a revolução de Rousseau, isto é, estima o espírito da ilustração e do seu desenvolvimento progressivo acima da revolução (MA I/HH I, $\S 463, \mathrm{KSA} 2.299)$. Vê o trabalho como empecilho ao livre exercício da razão (M/A, §173, KSA 3.154); critica, amiúde, a cultura de mercadores e os costumes praticados nas sociedades mercantis (M/A, §175, KSA 3.155-6), bem como a ideia do mínimo de Estado possível (M/A, §179, KSA 3.157-8). Anteviu que o surgimento de uma administração econômica total da Terra se tornaria inevitável. Embora temporalmente próximas, as obras datadas dos anos 1881 (Aurora) e 1882 (A gaia ciência) já não são tão positivas quanto à emancipação econômica dos indivíduos por meio do desenvolvimento progressivo derivado do espírito iluminista.

Nas obras da maturidade, o otimismo econômico de Nietzsche cessa completamente. Doravante, insurge-se contra a economia liberal; longe do mercado, na solidão, situa os inventores de novos valores (Za/ZA I, "Das moscas do mercado", KSA 4.65). O desenvolvimento de forças produtivas, sejam as do modo de produção liberal ou as do modo de produção escravista, decorrem da vontade de potência, por meio da qual seres humanos satisfazem não somente necessidades da existência material, antes ampliam seu domínio. Forças produtivas podem se desenvolver no sentido da organização de uma vontade de potência ascendente ou decadente. A economia liberal é vista como uma vontade de potência muito mais desagregadora do que uma vontade de potência hierárquica, segundo julga ocorrer na economia escravista. Eis por que Nietzsche cogita instituir uma elite de legisladores filósofos para governar a Europa enquanto uma unidade, para além dos nacionalismos pequenos, sob o controle de uma sociedade aristocrática, sustentada por um modo de produção 
Dias, G.

escravista (JGB/BM 239, KSA 5.177). Não encontrava saída mais adequada contra o "Liberalismo", que, "dito em alemão", para ele representa a "animalização em rebanho (GD/CI, IX 38, KSA 6.139).

$\mathrm{Na}$ avaliação de Nietzsche, o conceito de liberdade do liberalismo emerge das ideias modernas e possui uma conotação metafísica. Eis que ele apresenta a sua própria concepção de liberdade: "Liberdade significa que os instintos viris, que se alegram com a guerra e a vitória, têm predomínio sobre outros instintos, por exemplo, sobre o da "felicidade"" (GD/CI, IX 38, KSA 6.139-140). Contra o liberalismo, ele defende uma forma de aristocratismoescravista, capaz de contribuir para o triunfo de sua concepção de liberdade. Para tanto, ilustra que, historicamente, as "comunidades aristocráticas ao modo de Roma e Veneza entendiam liberdade no sentido em que" ele entende: "como algo que se tem e não se tem, que se quer, e que se conquista" (GD/CI, IX 38, KSA 6.140) ${ }^{7}$. E o liberalismo, por sua vez, bloquearia a emergência dessa liberdade, que só ocorreria em um contexto aristocrático.

\section{A "desorrorização" de Nietzsche e seu "curto- circuito historiográfico"}

Escritas no final do século XIX, quando predomina o otimismo decorrente do Iluminismo e do avançado desenvolvimento das técnicas de produção, de transporte e de comunicação, da democratização das oportunidades de educação e de trabalho, as obras de Nietzsche

\footnotetext{
7 Mas na república de Veneza do século XV, segundo Burckhardt, as coisas se passavam de outra maneira. Ele evidencia o perigo da nobreza empobrecida para a cidade. Os jovens nobres não se interessavam por política e uma parcela da nobreza estava desmoralizada. Havia, de um lado, os nobres ricos e, de outro, os nobres pobres, junto a uma separação rígida entre nobres e burgueses. "No interior da nobreza, por outro lado, as grandes empreitadas comerciais, as viagens e a participação nas sempre recorrentes guerras contra os turcos amputaram aos possíveis perigos - isto é, aos ricos - uma fonte capital de todas as conspirações: a ociosidade. Nas guerras, os comandantes os poupavam, por vezes de forma condenável, o que levou um Catão veneziano a profetizar a ruina da cidade, caso persistisse, em detrimento da justiça, esse receio dos nobres de causar sofrimento uns aos outros", cf. Burckhardt, 2009, p. 88-91.
}

158 | Cad. Nietzsche, Guarulhos/Porto Seguro, v.42, n.1, p. 145-172, janeiro/abril, 2021. 
portam uma visão econômica em desacordo com seu tempo, voltadas para uma forma de organização econômica baseada em privilégios. Sua proposta é radical: a classe social formada pelos nobres deve deter o monopólio do poder político e econômico. Estudioso e admirador das aristocracias nobres antigas e modernas, ele apostava na restauração de suas formas de organização econômica para deter, justamente, o avanço da civilização industrial, dos nacionalismos, do liberalismo e do socialismo. Ao longo de sua obra, mantém firme sua posição em favor da escravidão, "e não a espiritualizava, como muitos comentares do filósofo querem crer" (Silva Júnior, 2018, p. 31).

Para Ansell-Pearson, Nietzsche oferece a oportunidade de repensarmos as metas e os objetivos gerais da existência socioeconômica humana. Ao contrário de Vanessa Lemm, que nele vê uma economia da cultura não exploratória", ele pondera que o "pensamento político de Nietzsche baseia-se em uma justificação complexa e incomum de relações econômicas de exploração e dominação sob as quais o fenômeno da vida vem a ser". Seu aristocratismo, assentado na economia escravista, "é deficiente" e sem "legitimação", renuncia "a qualquer preocupação de se legitimar, exceto em função da problemática estética da "auto-superação do homem"” (AnsellPearson, 1997, p. 19-55).

Já para Celso Furtado, o fundamental é que com Nietzsche fica claro que a civilização industrial, com sua imensa burocracia, seja a da democracia liberal, seja a da economia planificada, subjuga a criatividade. Por outro lado, a economia das sociedades aristocráticas, ainda que condene a maioria a uma vida de escravidão, é a alternativa do filósofo para garantir a criatividade como privilégio de um único seguimento da sociedade. Furtado não apoiaria a legitimação estética

8 Partindo da distinção entre cultura e civilização, Lemm define duas diferentes economias de vida: de um lado, a economia da civilização, que representa um tratamento exploratório da animalidade, cujo objetivo é a autopreservação do grupo ao preço de normalizar o indivíduo e, de outro lado, a economia da cultura, que denota uma abordagem não exploratória da animalidade, dirigida para a pluralização de formas de vida singulares, cf. Lemm, 2019, p. 69. 
Dias, G.

de Nietzsche; nem acreditaria que sob o predomínio da razão teórica instrumentalizada repouse na sombra a ideia de uma cultura proveniente do sentimento trágico que, ao invés de retroceder a uma forma de organização social aristocrática e escravista, ressurgisse na forma de um esteticismo no qual a criatividade poderia ser realizada sem condicionamentos. A posição de Nietzsche sobre a criatividade, sobretudo a partir do Zaratustra, está associada ao conceito de vontade de potência; para a noção de que o caminho do criador valoriza a solidão e a individualidade e afasta-se do rebanho; rumando sempre para a autossuperação de si. Julga que o povo pouco compreende a criação; e que o "mundo gira ao redor dos inventores de novos valores" (Za/ZA I, "Das moscas do mercado", KSA 4.65). E a criação, como uma vontade de potência, que a tudo o que lhe oferece resistência tenta submeter e colocar a seu serviço, caracterizar-se-ia como força eficiente.

No plano econômico-político, esse conceito de criação não conflita com a visão de Nietzsche sobre a escravidão. Ele foi um anti-abolicionista. Há referências que sustentam essa posição. Numa delas, menciona a "Senhora Stowe", para referir-se a Harriet Beecher Stowe, autora do célebre romance antiescravista intitulado Uncle Tom's Cabin, de 1852. Essa menção revela familiaridade com os debates sobre o abolicionismo. Beecher Stowe aparece como seguidora iludida pela sedução de Rousseau, representando

a mulher, os escravos, os pobres, os trabalhadores e, enfim, o "sofrimento"; já as culturas grega e francesa da época de Luís $\mathrm{XIV}$, as vê como um "estamento de ociosos que tornam as coisas difíceis para si e praticam muito a autossuperação" (Nachlass/FP, 1884, 25[178], KSA 11.61-62). Nietzsche compara a condição dos trabalhares assalariados com a dos escravos antigos, qualificandoos como "trabalhadores da escravidão fabril" (M/A, §206, KSA 3.184-5). Nivela os escravos antigos e os trabalhadores modernos e dissuade que o desejo de "abolição da escravatura" (Aufhebung der 
Sclaverei) ocorre porque damos mais valor à vaidade do que a outras comodidades, como a segurança, a moradia. Porquanto o escravo antigo, como Diógenes, teria vivido de maneira mais segura e feliz do que o trabalhador moderno, que vive uma condição de excesso de trabalho, e sem a felicidade e segurança do escravo antigo (MA I/HH I, §457, KSA 2.296) ${ }^{9}$. Em cizânia com seu tempo, Nietzsche desloca as questões do trabalho moderno e da abolição da escravidão para o período antigo e as situam num plano axiológico, esvaziando-as do seu sentido político-social concreto relativo ao período contemporâneo.

São muitos os estudiosos de seu pensamento que ignoraram suas reflexões pró-escravidão ou convidam a lê-las metaforicamente. Louvando-o como um defensor da (auto) libertação, ignoram as suas argumentações contra a emancipação da mulher. Já do ponto de vista dos estudiosos que o leem segundo o método dialético, suas análises permitem ver o quanto ele desafia as suposições liberais e humanistas e o quanto o seu pensamento é conservador. É bem o caso de Domenico Losurdo, com seu Nietzsche, o rebelde aristocrata, que revela Nietzsche como o teórico do radicalismo aristocrático, além de demonstrar como se construiu a sua inocência ${ }^{10}$. Para além do círculo dos especialistas, observa-se que o fracasso de certos deles em enfrentar a defesa da escravidão feita pelo filósofo como "condição de toda cultura elevada" (JGB/BM, §239, KSA 5.177) teve custos: legou uma compreensão empobrecida de sua filosofia, uma vez que seus conceitos centrais estão ligados às suas ideias sobre ela (Ruehl, 2018, p 01).

Por isso, as tentativas de "desorrorização" (desororizzazione) de Nietzsche, como expressou Cesare Cases, buscaram meios

\footnotetext{
9 Em um esquema para uma reelaboração do livro Humano, demasiado humano, Nietzsche compendia uma espécie de sumário: "A favor da nobreza"; "Contra a abolição da escravatura" (Nachlass/FP, 1884-1885, 32 [20], KSA 11.417). Em outra anotação, identifica a "abolição da escravatura" como um traço niilista da "economia política" (Nachlass/FP, 1885-1886, 2 [131], KSA 12.130-131).

10 Sobre a interpretação de Losurdo, ver "Falsa polêmica por falso enquadramento: questão de método na leitura da filosofia nietzschiana feita por Losurdo", in: Silva Júnior, 2020, p. 69-82.
} 
Dias, G.

de atenuar aspectos horrorosos de seu pensamento. É fato que a refutação de Montinari das leituras ideológicas de Nietzsche não mantém continuidade com as atuais tentativas de inocentá-lo dos aspectos horrorosos escritos por ele mesmo, sem manipulação ou falsificação. O neologismo desororizzazione, empregado pelo crítico literário e germanista italiano Cesare Cases e criticado por Montinari, não guarda relação com o empreendimento crítico-filológico, no sentido de uma recuperação de Nietzsche do nazismo, supostamente realizada por Montinari (Montinari, 1999, p. 74). Por outro lado, uma vez superada a necessidade histórica de recuperação da obra de Nietzsche de apropriações indevidas, realizadas pelos movimentos ideológicos extremistas; desfeitas as falsificações e associações a seu respeito; uma vez estabelecidos os seus escritos segundo o método histórico-filológico, então devemos avançar no estudo dos aspectos problemáticos de seu pensamento. Isso é o que se pode fazer na pesquisa Nietzsche hoje. Mas não foi assim que ocorreu entre os anos de 1945 até o início da década de 1980. Nesse período, em torno de Nietzsche se produziu uma espécie de "curto-circuito historiográfico": se, por um lado, pesava o fato de terem sido reais as manipulações de seus textos e as interpretações ideológicas, por outro, seus aspectos horrorosos, como a afirmação da escravidão, o desprezo pelas mulheres e suas lutas por emancipação, sempre estiveram presentes na obra, embora esvaziados, ativamente esquecidos, purificados ou lidos como alegorias ou metáforas ${ }^{11}$.

Maria Cristina Fornari retoma e explora esse debate acerca da desorrorização de Nietzsche. Com razão, defende a escola surgida em torno da edição Colli-Montinari (agora digitalizada, corrigida e atualizada por Paolo D’Iorio, a Nietzsche Source) da acusação

11 As expressões desororizzazione e corto circuito storiografico são retomadas por Zumbini, aparecem em seu diálogo com Losurdo, cf. Zumbini, 2011 p. 39-45. Losurdo prefere a expressão "hermenêutica da inocência" (ermeneutica dell'innocenza): "no que diz respeito a Nietzsche, a hermenêutica hoje dominante transfigura em pura metáfora e em pura expressão artística a grandiosa tradução epistemológica e filosófica de um discurso eminentemente político", cf. Losurdo, 2009, p. 714-751.

162 | Cad. Nietzsche, Guarulhos/Porto Seguro, v.42, n.1, p. 145-172, janeiro/abril, 2021. 
de promover uma desorrorização da obra de Nietzsche. Ancorada na legítima autoridade que essa edição assegura, precipita sua consideração, expressa por D’Iorio, de que "Nietzsche é um autor difícil e aristocrático, que escrevia para poucos. Mas [que] sua aristocracia não é a do privilégio econômico e social"12. Consideração precipitada porque uma coisa são as condições de acesso aos textos do filósofo de maneira integral, isenta e segura e, uma vez postas essas condições, outra coisa é avaliar se há ou não em sua obra aspectos econômico-sociais e filosóficos conservadores. Estudos acerca dos

12 Fornari, 2019, p. 185. Não é tarefa fácil assumir o século XIX em Nietzsche. Ele não participa da expectativa comum do seu século de um progresso cultural e moral, nem dos ideais e movimentos democráticos dispostos a libertar os trabalhadores. Bem ao contrário, cogita que o futuro do médico poderia ser o da instauração de "uma aristocracia (Aristokratie) de corpo e de espírito (ao promover ou impedir matrimônios)" (MA I/HH I, §243, KSA 2.204); pensa que "As boas maneiras desaparecem à medida que se reduz a influência da corte e de uma aristocracia fechada" (MA I/HH I, §250. KSA 2.207); que "A riqueza produz necessariamente uma aristocracia da raça, pois permite escolher as mulheres mais belas, pagar os melhores professores, confere ao homem asseio, tempo para exercícios físicos e, acima de tudo, afastamento do trabalho físico embrutecedor" (MA I/HH I, §479, KSA 2.313). É sob o predomínio de valores aristocráticos (aristokratischer Werthe) que julga ocorrer a primeira tentativa de autoconhecimento moral (JGB/BM, §32, KSA 5.50); e que "O ceticismo em relação ao sofrimento, no fundo somente uma pose da moral aristocrática, concorreu em não pequena medida para a última grande rebelião de escravos, que teve início com a Revolução Francesa" (JGB/BM, $\S 46$, KSA 5.67); lamenta que "Em toda parte onde o espírito industrial venceu o espírito militar e aristocrático, a mulher aspira à independência econômica" (JGB/BM, §239, KSA 5.176); alega que "Toda elevação do tipo "homem" foi, até o momento, obra de uma sociedade aristocrática - e assim será sempre: de uma sociedade que acredita numa longa escala de hierarquia e diferenças de valor entre um e outro homem, e que necessita da escravidão em algum sentido" (JGB/BM, §257, KSA 5.205); afirma que em toda aristocracia sã, os indivíduos se tratam como iguais, mas, como vontade de potência encarnada, faz a outros tudo o que se abstêm de fazer uns aos outros (JGB/ BM, §259, KSA 5.207); e pensa que uma aristocracia se corrompe quando descarta seus privilégios por sentimento moral, pois nela o mais importante é ser o sentido de uma comunidade, que "aceite com boa consciência o sacrifício de inúmeros homens que, por sua causa, devem ser oprimidos e reduzidos a seres incompletos, escravos, instrumentos" (JGB/BM, §258, KSA 5.206). A visão de mundo de Nietzsche é aristocrática e ele mesmo aprovou como "muito boa" a expressão "radicalismo aristocrático" ("aristokratischer Radikalismus"), de Georg Brandes, para qualificar seu pensamento (eKGWB/BVN-1887,960 - carta a Georg Brandes: 02/12/1887). Conforme afirma Scarlett Marton: "Que Nietzsche tome a defesa do aristocratismo contra o ideal gregário, fica evidente quando se percorre os seus textos"; ele assume, assim, "posições com consequências políticas dificilmente defensáveis nos dias de hoje", cf. Marton, 2011, p. 17-33. Não estranha haver quem defenda que para Nietzsche até mesmo uma sociedade democrática precisa de uma aristocracia, ver Kaiser, 2006, p. 229-253. Nietzsche, se não pretendia, por um lado, o desenvolvimento da economia acumulativa técnicoindustrial capitalista, por outro lado, também não pretendia que ocorresse o desmantelamento do sistema econômico escravista das sociedades aristocráticas, ao contrário, lutava pela sua restauração. 
Dias, G.

aspectos conservadores do pensamento nietzschiano, comumente relegados como sendo destituídos de conteúdo filosófico, somente agora começam a avançar, uma árdua tarefa enfrentada por poucos. Entre esses poucos, Scarlett Marton se sobressai, com suas pesquisas acerca do que Nietzsche pensava sobre as mulheres ${ }^{13}$.

Em grande parte, a recepção do pensamento de Nietzsche na obra de Celso Furtado Celso Furtado ocorreu sob o impacto do curtocircuito historiográfico da desororizzazione de Nietzsche. Isto é, sob o influxo da hermenêutica da inocência, das tentativas de purificação dos aspectos conservadores de seu pensamento.

\section{O perspectivismo econômico crítico-filosófico de Celso Furtado}

Entretanto, a recepção da filosofia de Nietzsche na obra de Celso Furtado não ficou exclusivamente restrita ao impacto da "desorrorização" de Nietzsche e seu "curto-circuito historiográfico". Prova disso encontra-se desde os seus planos de escrever uma história da civilização brasileira "sob o ponto de vista críticofilosófico" (Furtado, 2019, p. 48). Celso Furtado desvela o mito do desenvolvimento e combate seus prolongamentos no Brasil ${ }^{14}$. Não é sem razão que Gerd Bornheim, às voltas com "o problema de uma filosofia especificamente nacional", encontre em Celso Furtado uma filosofia crítica da "ideologia desenvolvimentista", uma particular filosofia crítica independente e capaz de evidenciar o quanto a

13 Scarlet Marton discute se não seria Nietzsche um "pensador misógino" e revela em diversas passagens de seus escritos o "seu conservadorismo", cf. Marton, 2018, p. 26. Além de S. Marton, Ivo da Silva Júnior também enfrenta a tarefa de evidenciar aspectos conservadores do pensamento de Nietzsche, como a escravidão e a eugenia, cf. Silva Júnior, 2020, p. 269-280.

14 "A literatura sobre desenvolvimento econômico do último quarto de século nos dá um exemplo meridiano desse papel diretor dos mitos nas ciências sociais: pelo menos 90 por cento do que aí encontramos se funda na ideia, que se dá por evidente, segundo a qual o desenvolvimento econômico, tal qual vem sendo praticado pelos países que lideram a revolução industrial, pode ser universalizado", cf. Furtado, 1981, p. 14.

164 | Cad. Nietzsche, Guarulhos/Porto Seguro, v.42, n.1, p. 145-172, janeiro/abril, 2021. 
ideologia desenvolvimentista impregnou no Brasil, mas que não passa de expressão da vontade de uma classe dominante (Bornheim, 1998, p. 180).

Em suas principais obras, Celso Furtado fez da noção genérica de perspectiva seu ponto de vista crítico-filosófico sobre economia. Uma constante na sua obra é justamente a tentativa de expor suas reflexões e análises sobre economia a partir de uma visão perspectivista. Desde o clássico Formação econômica do Brasil, de 1959, para expor sua interpretação acerca da formação econômica do Brasil, Furtado adota uma estratégia chamada de "perspectiva ampla". Como ele diz, na introdução do livro, preocupou-se "em descortinar uma perspectiva o mais possível ampla" (Furtado, [1959] 2004, p. 07). Para expor sua interpretação acerca da formação econômica do Brasil, Furtado recorre a um olhar acima e afastado, uma perspectiva de pássaro, diria Nietzsche. A perspectiva ampla adotada the permite explorar e expor com dilatada visibilidade as forças, potências, valores e conflitos a partir dos quais examina os fundamentos econômicos da formação econômica do país. O olhar perspectivístico lhe garante a possibilidade de desvendar as teias e os tecidos histórico-sociais, as estruturas, que evidenciam as disputas pela posse dominadora e exploratória das riquezas disponíveis. Com esse olhar, pôde distinguir as diferentes posições das potências que disputavam o domínio da colônia. Não sobrepôs uma perspectiva sobre outra, cada uma coexiste com outras perspectivas. As condições materiais são descritas em perspectiva ampla, não toca nem menciona agentes econômicos menores, não trata da economia do pau-brasil, nem do escambo, praticado nos primeiros anos de exploração. Sua perspectiva ampla capta com precisão as macro-etapas da formação econômica, como a economia do açúcar, a economia criatória, a economia mineira. Transita, assim, da economia escravocrata até a do trabalho assalariado do sistema industrial. O perspectivismo de Celso Furtado é precisamente a maneira pela qual ele próprio realizou uma 
Dias, G.

forma de criatividade livre. Procurou ver através, ver em perspectiva ampla as características fundamentais do desenvolvimento econômico da civilização industrial, da época moderna até nossos dias. Recebeu Nietzsche como o pensador que lhe sugeriu a consciência generalizada do caráter instrumental niilista do conhecimento e da criatividade, capazes, ainda assim, de proporcionar um autoconhecimento que é condição de superação do niilismo da subordinação da criatividade ao racionalismo instrumental capitalista.

Mas, o que significa mais precisamente investigar a economia de uma perspectiva ampla? O ponto principal de Celso Furtado é captar o comportamento econômico do ser humano numa "perspectiva suficientemente ampla" (Furtado, [1957] 1960, p. 10-11); numa perspectiva ampla do produto e da renda, dos valores morais e das transformações estruturais mais significativas ocorridas na história. Foi sempre de uma perspectiva ampla do processo histórico que ele procurou desvelar o imobilismo estrutural da sociedade brasileira. Não nega seu carecimento por perspectivas para globalizar, para captar o sentido dos processos que determinam o curso dos acontecimentos econômicos; evidencia o quanto os homens ficam inebriados pela perspectiva do fluxo de grandes riquezas. Digamos que, a partir de Nietzsche, Celso Furtado pensa o que há de perspectivista na economia, seus deslocamentos globais, a disposição e a aparente teleologia acumulativa de seus horizontes e a tudo o que se relaciona às perspectivas que a compõem. Em suas pesquisas, Furtado concebe a economia como constituída por uma multiplicidade de perspectivas, como a dos preços, a do mercado, a da política; trabalha com perspectivas de longa duração, considera outras de curta duração; pensa e milita pelo desenvolvimento da economia regional; não desconsidera a perspectiva da economia estatal/nacional, nem sua relação conflituosa com a perspectiva global/capitalista. Assim, Celso Furtado pensa "a noção de desenvolvimento econômico dentro de 
uma perspectiva interdisciplinar e filosófica"15. Para além da reflexão especificamente econômica, com Nietzsche Celso Furtado conseguiu avistar o caráter perspectivista não só da economia, mas da própria existência material dos seres humanos e seus desdobramentos no plano espiritual, isto é, da criação de valores, do ser humano como um gênio criador de valores. Dessa forma, é possível observar, na obra de pensamento de Celso Furtado, a coerência interna de um sistema conceitual crítico-filosófico sobre economia.

15 Celso Furtado vincula a noção de desenvolvimento "às ideias de progresso, riqueza e dominação", inserindo-a "na racionalidade instrumental do capitalismo". Com efeito, evidencia "uma pluralidade de sentidos do conceito de desenvolvimento, mas também para a problemática que lhe é inerente, com destaque para a questão do subdesenvolvimento", cf. Szmrecsányi, 2020, p. 58. 
Dias, G.

\title{
The reception of Nietzsche's philosophy in the work of Celso Furtado
}

\begin{abstract}
Taking into account that 2020 was the year of celebration of the centenary of Celso Furtado's birth, as a simple tribute, in this article we seek to offer a preliminary introduction on the reception of Nietzsche's philosophy in the work of the Brazilian economist. Celso Furtado is one of the most influential thinkers in the field of political economy in Latin America. But no one has yet researched his philosophical dimension of thought. Nevertheless, it is possible to say that he thought economics from a critical-philosophical point of view. To prove this hypothesis, we intend to highlight three conceptual aspects that he appropriated from Nietzsche's philosophy. They are: creativity and / or creation (Schaffung), to think about its role as a driving agent for the development of industrial civilization; the transvalue of all values (Umwerthung aller Werthe), to think about the relevance of moral values to the decision-making centers of the means and ends of capital production and distribution; and perspectivism (Perspektivismus), to think of the economy as a totality composed of multiple structural perspectives. Keywords: Nietzsche, reception, Celso Furtado, creativity, moral values, perspectivism.
\end{abstract}

\section{Referências}

ANSELL-PEARSON, Keith. Nietzsche como pensador político: uma introdução. Trad. Mauro Gama, Cláudia Martinelli. Rio de Janeiro, Jorge Zahar Ed. 1997.

BORNHEIM, Gerd. "Filosofia e realidade nacional". In: O Idiota e o Espírito Objetivo. Rio de Janeiro: UAPÊ, 1998.

BOSI, Alfredo, "Prefácio". In: FURTADO, Criatividade e dependência na civilização industrial. São Paulo: Companhia das Letras, 2008.

168 | Cad. Nietzsche, Guarulhos/Porto Seguro, v.42, n.1, p. 145-172, janeiro/abril, 2021. 
BURCKHARDT, Jacob. A cultura do Renascimento na Itália: um ensaio. Trad. Sérgio Tellaroli. São Paulo: Companhia das Letras, 2009.

BRUGNERA, Nedilso Lauro. A escravidão em Aristóteles. Porto Alegre: EDIPUCRS, Editora Grifos, 1998.

FORNARI, M. C. Uma aventura de mais de um século: a história das edições de Nietzsche. São Paulo: Editora Unifesp, 2019.

FURTADO, Celso. Perspectivas da Economia Brasileira. D. A. S. P., Serviço de Documentação, ([1957] 1960]).

. Formação econômica do Brasil. $33^{\text {a }}$ edição. São Paulo: Companhia Editora Nacional, ([1959] 2004.

.O mito do desenvolvimento econômico. $4^{\text {a }}$ edição. São Paulo, Círculo do livro, ([1961] 1981).

. Teoria e política do desenvolvimento do econômico. São Paulo: Abril Cultural, ([1967] 1983).

. Criatividade e dependência na civilização industrial. Edição definitiva. São Paulo: Companhia das Letras, ([1978] 2008).

. Obra autobiográfica. $1^{\text {a }}$ ed. São Paulo: Companhia das Letras, 2014.

. Diários intermitentes: 1937-2002. $1^{\mathrm{a}}$ ed. São Paulo: Companhia da Letras, 2019.

HELLER, Agnes. A filosofia radical. Trad. Carlos Nelson Coutinho. São Paulo: Brasiliense, 1983.

KAISER, Otto, "Democracy and Aristocracy in Nietzsche's Late Writings". In: Friedrich Nietzsche (1844-1900): Economy and Society. Jürgen G. Backhaus; Wolfgang Drechsler (orgs.). New York, Springer, p. 229-253, 2006.

LEMM, Vanessa. Cultura e economia em Nietzsche. In: Cad. Nietzsche, Guarulhos/ Porto Seguro, v.40, n.1, p. 67-91, janeiro/abril, 2019.

LOSURDO, Domenico. Nietzsche: o rebelde aristocrata: biografia intelectual e balanço crítico. Trad. Jaime A. Clasen. Rio de Janeiro: Renan, 2009. 
Dias, G.

MARTON, Scarlett. "Nietzsche e a crítica da democracia". In: Dissertatio, UFPel, Pelotas, RS, vol. 33, p. 17-33, 2011.

" "GEN - uma experiência de formação". In: Cadernos Nietzsche. São Paulo, n.30, pp. 303-319, 2012.

. Nietzsche, Pensador misógino? In: Cult, São Paulo, p. 26-29, 01 jul. 2018.

MONTINARI, Mazzino. "Interpretações nazistas". In: Cadernos Nietzsche. São Paulo, n.7, p. 55-77, 1999.

NIETZSCHE, Friedrich. "O estado grego". In: Cinco prefácios para cinco livros não escritos. Trad. Pedro Süssekind. $4^{\mathrm{a}}$ ed. Rio de Janeiro, 7 Letras, ([187073] 2007).

. O nascimento da tragédia, ou, Os gregos e o pessimismo. Trad. e notas Paulo César de Souza. 1 $1^{\text {a }}$ ed., São Paulo. Companhia de Bolso, ([1872] 2020).

. Humano, demasiado humano: um livro para espiritos livres. Trad. Paulo César de Souza. São Paulo: Companhia das Letras, ([1878] 2000).

. Humano, demasiado humano: um livro para espíritos livres volume II. Primeira parte: Opiniões e sentenças diversas. Segunda parte: $O$ andarilho e sua sombra. Trad. Paulo César de Souza. São Paulo: Companhia das Letras, ([1879-80] 2008).

. Aurora. Reflexões sobre os preconceitos morais. Trad. Paulo César de Souza. São Paulo: Companhia das Letras, ([1881] 2004).

. A gaia ciência. Trad. Paulo César de Souza. São Paulo: Companhia das Letras, ([1882] 2001.

. Assim falou Zaratustra: um livro para todos e para ninguém. Trad. Paulo César de Souza. São Paulo: Companhia das Letras, ([1883-85] 2011).

. Além do bem e do mal: prelúdio a uma filosofia do futuro. Trad. Paulo César de Souza. São Paulo: Companhia das Letras, ([1886] 1992).

. Crepúsculo dos ídolos, ou, Como se filosofa com o martelo. Paulo César Souza. São Paulo: Companhia das Letras, (1888] 2006).

170 | Cad. Nietzsche, Guarulhos/Porto Seguro, v.42, n.1, p. 145-172, janeiro/abril, 2021. 
. Werke. Kritische Studienausgabe (KSA). Berlim/New York: Walter de Gruyter \& Co., ([1967-78] 1999), 15v.

. Digitale Kritische Gesamtausgabe. Werke und Briefe, Paolo D'Iorio (org.), Paris, Nietzsche Source, http://www.nietzschesource.org/eKGWB, 2009.

. Friedrich Nietzsche. Obras incompletas. Seleção de textos de Gérard Lebrun; Trad. E Notas de Rubens Rodrigues Torres Filho. Posfácio de Antonio Candido. São Paulo: Editora 34, 2014.

QUINTELA, Adroaldo. Celso Furtado: os combates de um economista. Organizadores: Adroaldo Quintela [et al.]. São Paulo: Fundação Perseu Abramo: Expressão Popular, 2020.

REINERT, Hugo e Erik S. Reinert, "Creative Destruction in Economics: Nietzsche, Sombart, Schumpeter". In: Friedrich Nietzsche (1844-1900): Economy and Society. Jürgen G. Backhaus; Wolfgang Drechsler (orgs.). New York, Springer, p. 55-135, 2006.

RUEHL, Martin. In defence of slavery: Nietzsche's dangerous thinking. In: Independent. Janeiro, 2018. Acessado entre 20/08/2019 e 28/02/2020: disponível, em: https:// www.independent.co.uk/news/long_reads/nietzsche-ideas-superman-slaverynihilism-adolf-hitler-nazi-racism-white-supremacyfascism-a8138396.html.

SILVA JÚNIOR, Ivo da. Em busca de um lugar ao sol: Nietzsche e a cultura alemã. SP, Discurso Editorial; Ijuí, RS: Editora UNIJUÍ, 2007.

. "Capitalisme" e "Libéralisme". In: Dictionnaire Nietzsche. Paris: Robert Laffont, p. 119-120 e 538-540, 2017.

. Escravidão, trabalho e ócio. In: Cult, n. 236, São Paulo, p. 30-33, 2018.

. "Saúde, doença e eugenia em Nietzsche". In: La question de la médecine dans la philosophie de Nietzsche. IXe Congrès International du GIRN. Schwabe Verlag, Schwabe Verlagsgruppe AG, Basel, Schweiz, p. 269-280, 2020.

. "Falsa polêmica por falso enquadramento: questão de método na leitura da filosofia nietzschiana feita por Losurdo". In: Nietzsche e seus intérpretes. Vânia Dutra de Azeredo, Wilson Antonio Frezzatti (organizadores). Curitiba: CRV, (Coleção Nietzsche em Perspectiva - volume 3), p. 69-82, 2020. 
Dias, G.

SZMRECSÁNYI, Tomás, “Celso Furtado”. In: Celso Furtado a esperança militante (Interpretações), vol. 1. [livro eletrônico], Cidoval Morais de Sousa, Ivo Marcos Theis, José Luciano Albino Barbosa (organizadores), Campina Grande: EDUEPB, 2020.

ZUMBINI, Massimo Ferrari. Nietzsche: storia di un processo politico. Dal nazismo alla globalizzazione. Rubbettino Editore, Itália, 2011.

Enviado: 11/10/2020

Aceito: $15 / 12 / 2020$

172 | Cad. Nietzsche, Guarulhos/Porto Seguro, v.42, n.1, p. 145-172, janeiro/abril, 2021. 